\title{
Detection of the gas-saturated zone by spectral decomposition using Wigner-Ville distribution for a thin layer reservoir
}

\author{
Sungil Shin and Joongmoo Byun* \\ Department of Natural Resources and Geoenvironmental Engineering, Hanyang University \\ 얇은 저류층 내에서 WVD 빛띠 분해에 의한 가스 포화 구역 탐지 \\ 신승일 · 변중무* \\ 한양대학교 자원환경공학과
}

\begin{abstract}
Recently, stratigraphic reservoirs are getting more attention than structural reservoirs which have mostly developed. However, recognizing stratigraphic thin gas reservoirs in a stacked section is usually difficult because of tuning effects. Moreover, if the reflections from the brine-saturated region of a thin layer have the same polarity with those from the gas-saturated region, we could not easily identify the gas reservoir with conventional data processing technique. In this study, we introduced a way to delineate the gas-saturated region in a thin layer reservoir using a spectral decomposition method. First of all, amplitude spectrum with the variation of the frequency and the incident angle was investigated for the medium which represents property of Class 3, Class 1 or Class 4 AVO response. The results show that the maximum difference in the amplitude spectra between brine and gas-saturated thin layers occurs around the peak frequency independent of the incident angle and the type of AVO responses. In addition, the amplitude spectra of the gas-saturated zone are greater than those of brine-saturated one in Class 3 and Class 4 at the peak frequency while those of phenomenon occur oppositely in Class 1 . Based on the results, we applied spectral decomposition method to the stacked section in order to distinguish the gas-saturated zone from the brine-saturated zone in a thin layer reservoir. To verify our new method, we constructed a thin-layer velocity model which contains both gas and brine-saturated zones which have the same reflection polarities. As a result, in the spectral decomposed sections near the peak frequency obtained by Wigner-Ville Distribution (WVD), we could identify the difference between reflections from gas- and brinesaturated region in the thin layer reservoir, which was hardly distinguishable in the stacked section.
\end{abstract}

Keywords: spectral decomposition, thin layer reservoir, amplitude spectrum

요 약: 최근에는 지금까지 주로 탐사개발이 이루어진 구조적 저류층보다 층서적 저류층에 대한 관심이 높아지고 있다. 하지만 얇은 두께의 가스 저류층의 경우 동조효과로 인해 겹쌓기 단면도에서 탐지가 어렵다. 게다가 얇은 저류층 내 염 수가 있는 부분과 가스로 치환된 부분으로부터의 반사파가 동일한 극성을 갖는 경우 일반적인 자료 처리 기술을 이용해 서 가스가 있는 부분을 규명하는 것이 쉽지 않다. 본 연구에서는 빛띠 분해를 이용해서 얇은 저류층 내 가스로 치환된 부분을 나타내는 방법을 소개하고자 한다. 먼저, Class 1, Class 3 그리고 Class 4의 AVO 반응을 가지는 매질의 물성을 이용하여 다양한 입사각과 진동수에 따른 진폭 빛띠를 분석하였다. 그 결과 입사각과 AVO 종류에 무관하게 최대 진폭 빛띠 값을 갖는 꼭지 진동수 근처에서 염수와 가스로 치환된 얇은 층의 진폭 빛띠 값이 가장 크게 차이가 나는 것을 확 인하였다. 또한 Class 3와 Class 4의 성질을 가지는 매질에서는 가스로 치환된 부분의 진폭 빛띠가 꼭지 진동수에서 염 수로 치환된 부분의 진폭 빛띠보다 크게 나타나는 것을 확인하였고 이러한 현상은 Class 1 에서는 반대로 일어나는 것을 확인하였다. 위의 결과를 토대로 얇은 저류층내에서 가스로 치환된 부분을 염수로 치환된 부분과 구분하기 위해서 겹쌓 기 단면에 빛띠 분해법을 적용하였다. 위 방법에 대한 타당성을 검증하기 위해서 동일한 반사 극성을 가지면서 염수와 가스로 치환된 부분이 모두 있는 하나의 얇은 저류층 속도 모델을 설정하였다. 결과적으로 Wigner-Ville distribution을 사 용해서 얻은 꼭지 진동수 근처에서의 빛띠 분해 단면도를 통해 겹쌓기 단면에서는 구분이 어려웠던 얇은 저류층 내에서 의 염수와 가스로 치환된 부분을 구분할 수 있었다.

\footnotetext{
Manuscript received December 5, 2011; accepted January 16, 2012;

*Corresponding author

E-mail: jbyun@hanyang.ac.kr

Address: Dept. of Natural Resources and Geoenvironmental Engineering, Hanyang University, 17 Haengdang1-dong, Seongdong-gu, Seoul, Korea
} 


\section{Introduction}

Recognizing the existence of hydrocarbon in the reservoir is one of the main important issues in oil exploration. Therefore, many techniques have been developed such as direct hydrocarbon indicators in stacked section or AVO (Amplitude Variation with Offset) analysis. However, when the thickness of the reservoir is less than the fourth of the dominant wavelength, called thin layer reservoir, it is hard to use conventional technique analyzing the reflection amplitudes, because of wavelet tuning. Tuning effect is that the amplitudes of the reflection event from upper boundary of the reservoir are interfered and distorted by those from its lower boundary.

On the other hand, the tuning effect from the thin layer reservoir and spectral decomposition has been widely applied in identifying the thin layer reservoir and its thickness (Partyka et al., 1999; Marfurt and Kirlin, 2001). Especially, Liu and Marfurt (2006) have predicted the thickness of the thin layer by using the amplitude spectrum.

To overcome the problems occurred in detecting gas saturated part of the thin layer reservoir, Ren et al. (2007) suggested mapping technique named the Spectra Cross plot, which integrate crossplot and spectra analysis, in order to distinguish gas-saturated zone from brine-saturated zone in the thin reservoir which shows Class 2 AVO responses. However, it is ambiguous to determine the boundary of the values corresponding to the gas-saturated zone in the cross plot.

In this study, first of all, we analyzed the change in the amplitude spectrum with the variation of frequency and incident angle depending on the pore fluid by using the amplitude spectrum function (Liu and Marfurt, 2006). The difference between the amplitude spectrum functions of the thin reservoir for Class 3, Class 1 and Class 4 was also examined. In addition, based on the results of analysis, we introduced an efficient method to detect gas-saturated thin layers in the stacked section by using spectral decomposition.

\section{Amplitude spectrum function}

The amplitude spectrum function $R(f)$ of the thin bed reflection response which computes the amplitude for each frequency with incident angle was introduced by Liu and Marfurt (2006).

$$
R(f)=\sqrt{r_{1}^{2}+r_{2}^{2}+2 r_{1} r_{2} \cos (2 \pi f \Delta t)},
$$

where $r_{1}$ and $r_{2}$ are the reflection coefficients of top and bottom of the thin layer, respectively. Liu and Schmitt (2003) approximated the time delay $\Delta t$ as

$$
\Delta t \approx \frac{2 d \cos (\theta)}{\alpha_{2}}
$$

where $d$ and $\alpha_{2}$ are the thickness and P-wave velocity of the thin layer, respectively, and $\theta$ is the average of incident and transmitted angles.

\section{Wigner-Ville distribution}

Spectral decomposition is a powerful tool in detecting the gas reservoir. Several methods - such as STFT (Short-Time Fourier Transform), CWT (Continuous Wavelet Transform), MP (Matching Pursuit), and WVD (Wigner-Ville Distribution) - have been used in spectral decomposition. Among them, WVD is getting attention for spectral decomposition because of the resolution in both time and frequency due to the absence of a window in calculating the time-frequency representations (Ralston et al., 2007). The WVD of signal $x(t)$ can be expressed as

$$
W(t, \omega)=\frac{1}{2 \pi} \int x(t+\tau / 2) x^{*}(t-\tau / 2) e^{-j \tau \sigma} d \tau,
$$

where $\tau$ is the delay variable and $x^{*}(t)$ is the complex conjugate of $x(t)$. Recently, the WVD was improved by filtering the cross-term and has proved its potential application to reservoir characterization ( $\mathrm{Li}$ and Zheng, 2008; Wu and Liu, 2009).

\section{Analysis of amplitude spectrum function}

In order to survey the effects of incident angle and fre-

Table 1. Rock properties used in the analysis of amplitude spectrum.

\begin{tabular}{cccc}
\hline \hline [Class 1] & Vp $(\mathrm{m} / \mathrm{s})$ & Vs $(\mathrm{m} / \mathrm{s})$ & $\rho\left(\mathrm{g} / \mathrm{cm}^{3}\right)$ \\
\hline Shale 1 & 3094 & 1515 & 2.4 \\
Wet sandstone & 4115 & 2453 & 2.32 \\
Gas saturated sandstone & 4050 & 2526 & 2.21 \\
Shale 2 & 3146 & 1554 & 2.41 \\
\hline [Class 3] & Vp $(\mathrm{m} / \mathrm{s})$ & Vs $(\mathrm{m} / \mathrm{s})$ & $\rho\left(\mathrm{g} / \mathrm{cm}^{3}\right)$ \\
\hline Shale 1 & 2192 & 818 & 2.16 \\
Wet sandstone & 2134 & 860 & 2.11 \\
Gas saturated sandstone & 1967 & 1100 & 2.095 \\
Shale 2 & 2240 & 857 & 2.18 \\
\hline [Class 4] & Vp (m/s) & Vs $(\mathrm{m} / \mathrm{s})$ & $\rho\left(\mathrm{g} / \mathrm{cm}^{3}\right)$ \\
\hline Shale 1 & 3240 & 1620 & 2.34 \\
Wet sandstone & 2590 & 1060 & 2.21 \\
Gas saturated sandstone & 2006 & 1070 & 2.165 \\
Shale 2 & 3000 & 1600 & 2.3 \\
\hline & & & \\
\hline & & & \\
\hline & & & \\
\hline
\end{tabular}




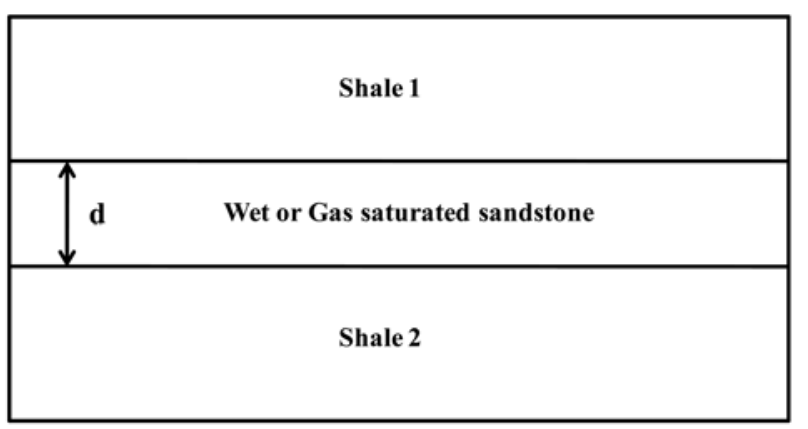

Fig. 1. Simple model used in analyzing the amplitude spectrum function.

quency on the amplitude spectrum function, we observed amplitude spectrum function for the media with Class 3, Class 4 and Class 1 AVO responses at both 100\% saturated brine- and $30 \%$ gas-saturated cases. The parameters used in calculating the amplitude spectrum function were taken from Hilterman (2001) and listed in Table 1. The 1/8 wavelength was used as a thickness of the thin-layer reservoir for each AVO cases by using the relation between the main frequency of the source and the velocity. In this study, we used $30 \mathrm{~Hz}$ as the main frequency of the source. Fig. 1 shows a simple model used for analyzing the amplitude spectrum function. In our experiment, $d$ is the thickness of the thin-layer reservoir which depends on the velocity of the thin-layer which is determined by the source main frequency and the wavelength.

\section{Class 3 formation}

First of all, we observed the variation in the amplitude spectra with incident angle for the medium with Class 3 AVO response which is the most common AVO response from gas reservoir. Fig. 2a, Fig. $2 b$ and Fig. $2 c$ show the tendency of amplitude spectra with the frequency when the incident angle is $0^{\circ}, 10^{\circ}$ and $25^{\circ}$, respectively. As shown in Fig. 2, the values of the amplitude spectrum are getting greater with increasing the incident angle as same as the response of Class 3 medium. Note that the value of the amplitude spectra is absolute value due to amplitude spectrum function.

Also, the amplitude spectra of the gas-saturated thin layer (solid line) are greater than those of the brine-saturated thin layer (dashed line) for every frequency. The results arise from the difference in the P-wave velocity between the shale and the gas-saturated sandstone is bigger than that between brine-saturated shale and sandstone. And similar amplitude spectrum appears with cycles which depend on the thickness of the thin layer, even though we present the results until

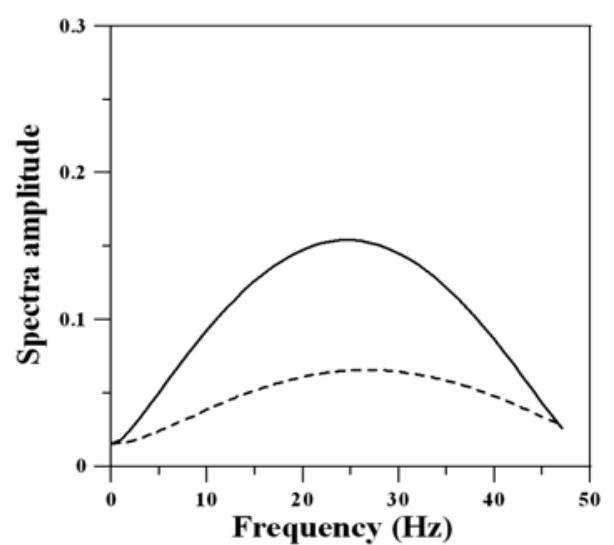

(a)

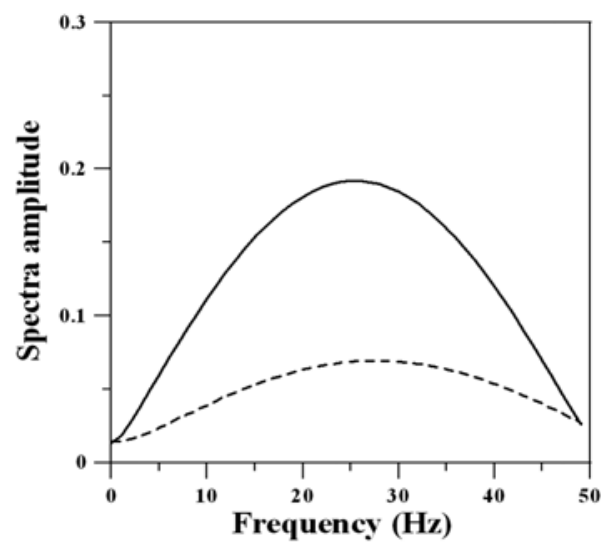

(b)

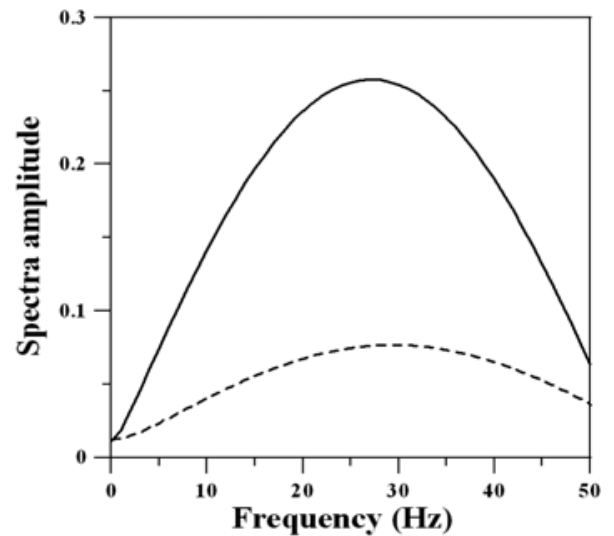

(c)

Fig. 2. The amplitude spectra of Class 3 with the variation of frequency at incident angle (a) $0^{\circ}$, (b) $15^{\circ}$ and (c) $25^{\circ}$. Dashed and solid lines indicate brine- and $30 \%$ gas-saturated thin layers, respectively.

only $50 \mathrm{~Hz}$ as shown in Fig. 2. In our case of class 3 thin layer reservoir, the amplitude spectra have the peak values around $25 \mathrm{~Hz}$ called the peak frequency in both brine- and gas-saturated thin layer.

More detailed results are shown in Fig. 3 by analyzing the amplitude spectra with the frequency and the incident angle 


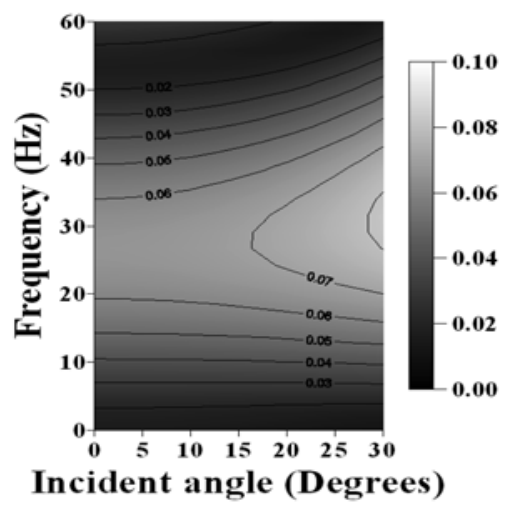

(a)

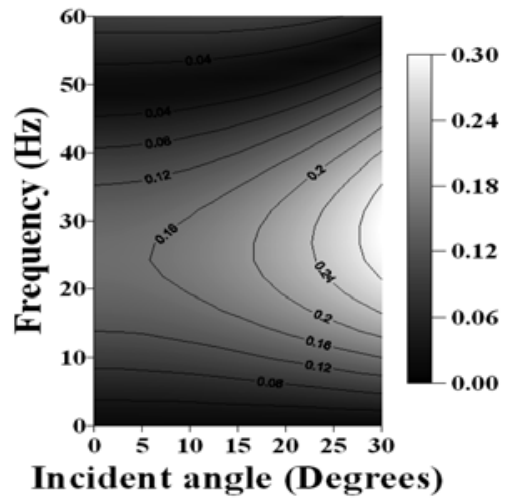

(b)

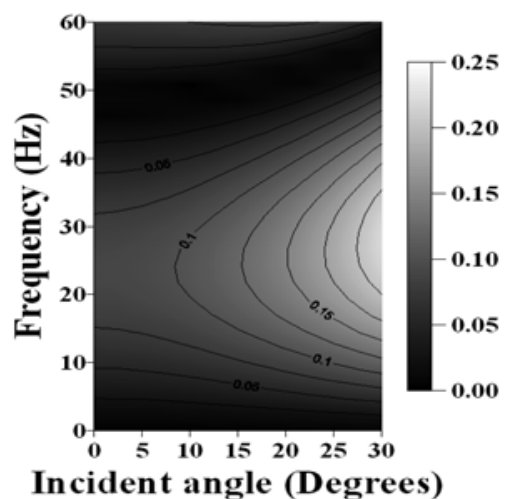

(c)

Fig. 3. Spectral diagrams of (a) brine-saturated and (b) gas-saturated zones for Class 3 formation with the variation of the frequency and the incident angle. (c) is the difference between (a) and (b). Note the scale bars indicate amplitude value.

for brine- and gas-saturated zones in Class 3 reservoir and its differences, respectively. Similarly to the results shown in Fig. 2, we can easily notified the peak frequencies are around $25 \mathrm{~Hz}$ regardless of the incident angle and the pore fluids. Therefore, we confirmed that the maximum difference in the amplitude spectrum between brine- and gas-saturated thin layers occur around the peak frequency regardless of incident angle as shown in Fig. 3c. In addition, with increas-

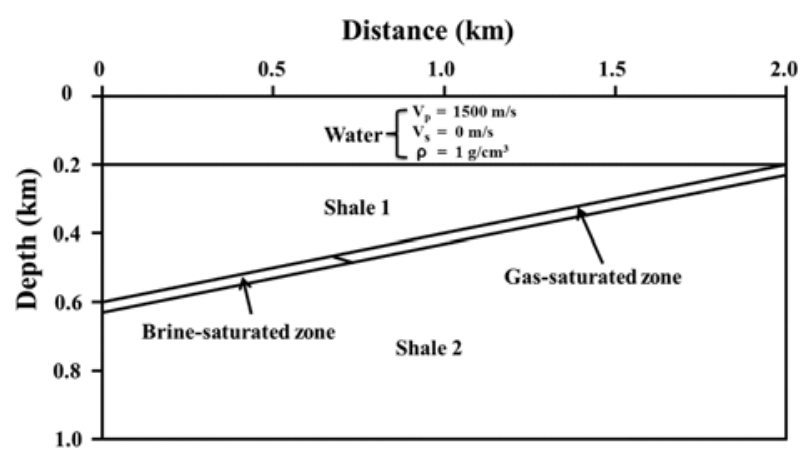

Fig. 4. Velocity model used to create synthetic data by using rock properties in Table 1. Note that right upper part and left lower part indicate the brine- and gas-saturated region of thin dipping reservoir, respectively.

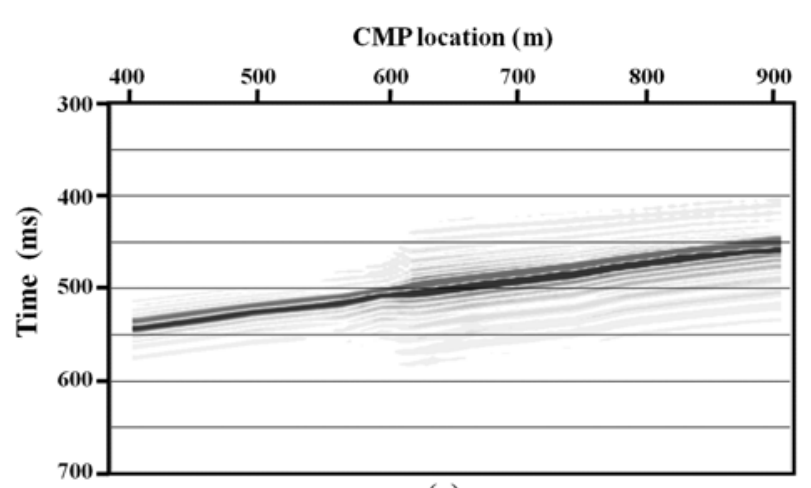

(a)

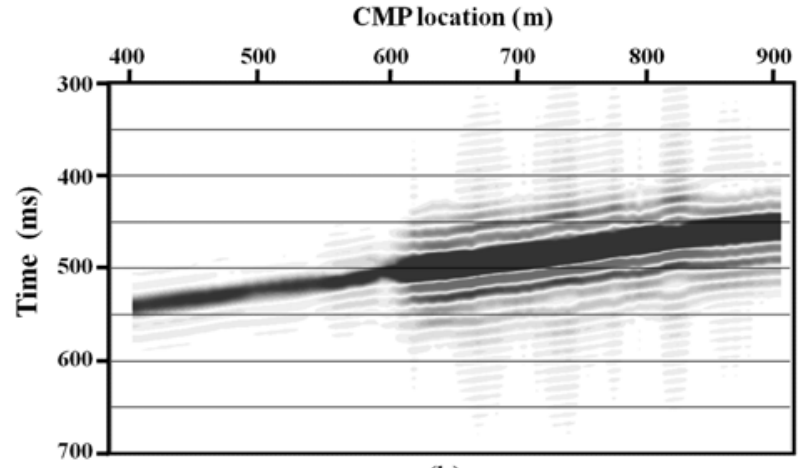

(b)

Fig. 5. (a) Stacked section with Class 3 medium. (b) Spectral decomposed section at $25 \mathrm{~Hz}$.

ing incident angle, the large difference in amplitude spectrum between gas- and brine-saturated reservoir for wider frequency ranges.

Consequently, we made the inference that brine- and gassaturated part of the thin layer reservoir can be discriminated more clearly at frequencies around the peak frequency. To verify our suggestion, we constructed the velocity model containing a thin dipping reservoir saturated partially with gas. The upper part of the thin reservoir was saturated with 
gas and its lower part was saturated with brine (Fig. 4). The same parameters as listed in Table 1 were used in numerical modeling with the $10 \mathrm{~m}$ thickness of the thin layer and source main frequency. Synthetic seismic data were generated based on the ray theory by using the commercial soft-

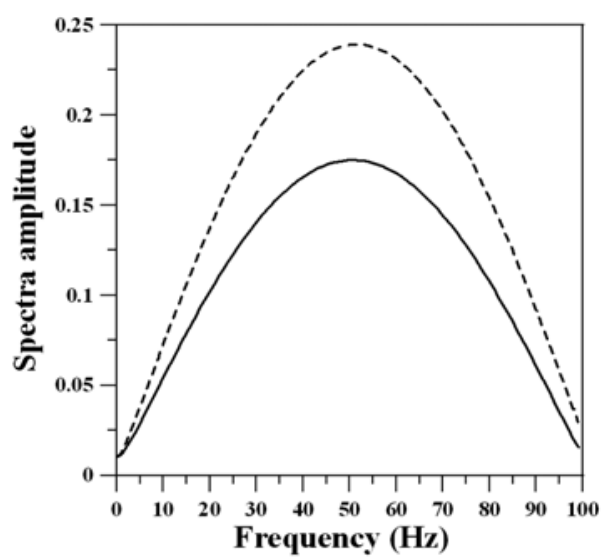

(a)

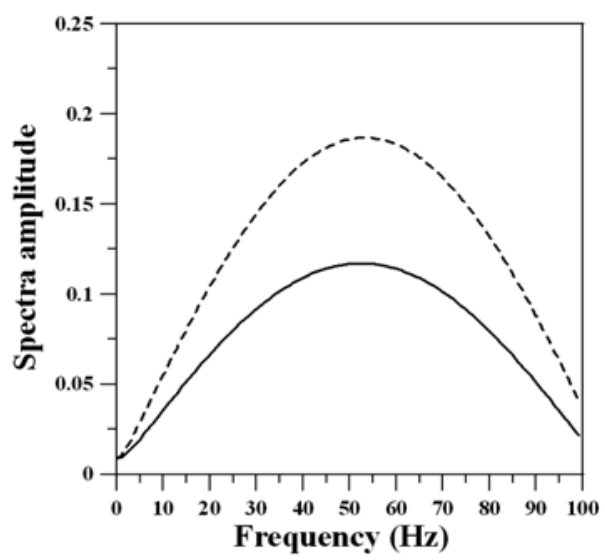

(b)

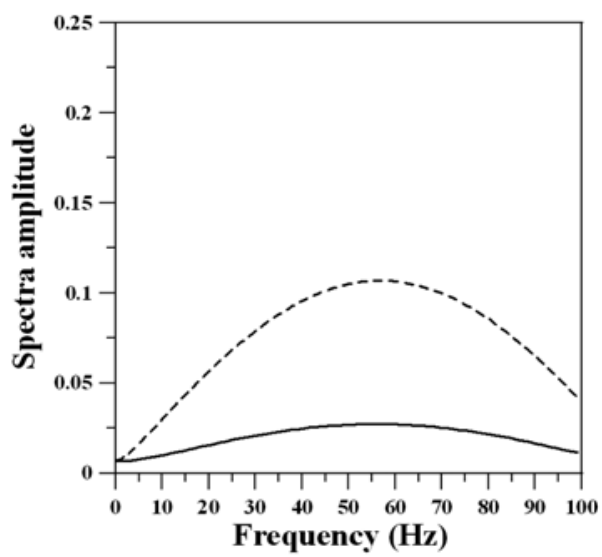

(c)

Fig. 6. The amplitude spectra of Class 1 with the variation of frequency at incident angle (a) $0^{\circ}$, (b) $15^{\circ}$ and (c) $25^{\circ}$. Dashed and solid lines indicate brine- and gas-saturated thin layers, respectively. ware which was developed by ION. 51 shots with $20 \mathrm{~m}$ interval and 101 receivers with $10 \mathrm{~m}$ interval were used as survey parameters, respectively. The recording lengths of the synthetic data sets are set to $2 \mathrm{sec}$ with $2 \mathrm{~ms}$ sampling interval.

If the reflections from the both brine- and gas-saturated regions have the same polarity and the difference between the velocity of the brine-saturated zone and that of the gassaturated zone is small, the identification of gas-saturated

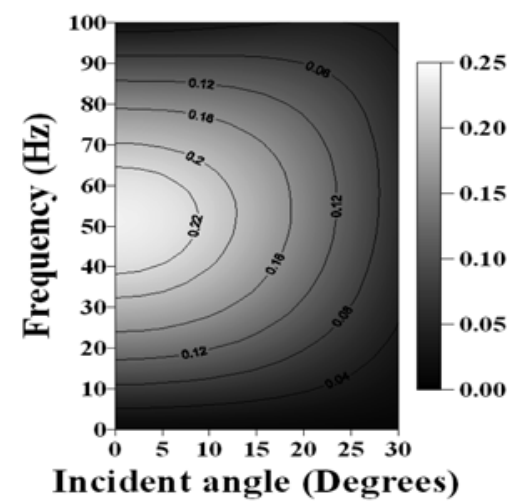

(a)

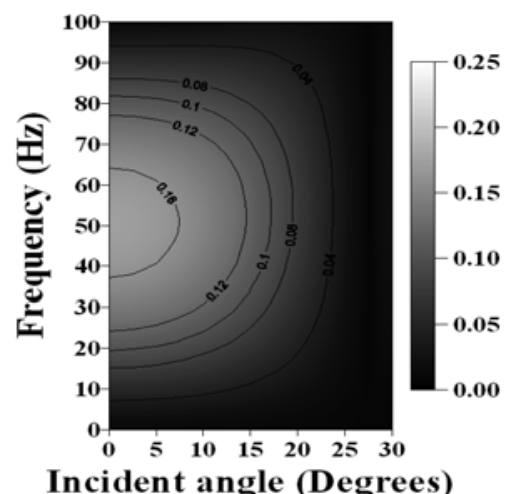

Incident angle (Degrees)

(b)

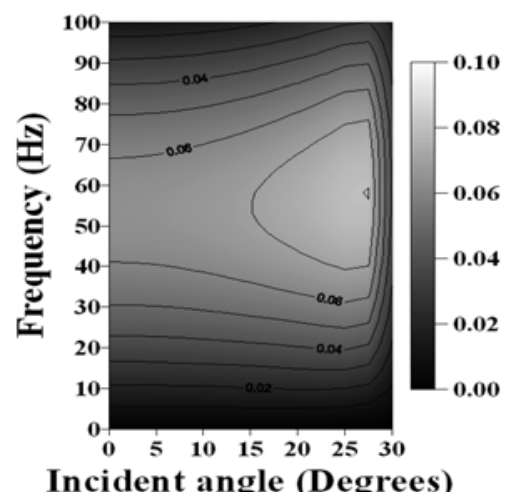

(c)

Fig. 7. Spectral diagrams of (a) brine-saturated and (b) gassaturated zones for Class 1 formation with the variation of the frequency and the incident angle. (c) is the difference between (a) and (b). Note the scale bars indicate amplitude value. 
zone in the stacked section is difficult as shown in Fig. 5a. Even it looks like a reflection event from a single geological boundary. Following our method, we applied spectral decomposition to the stacked section and decomposed this reflection event into each frequency component to obtain decomposed section for each frequency within $0 \mathrm{~Hz}$ and 120 $\mathrm{Hz}$. Then we examined the decomposed section at frequencies around the peak as we analyzed above. Fig. 5b show the decomposed section at $25 \mathrm{~Hz}$, which is corresponding to the peak frequency of gas-saturated zone. As shown in the Fig. 5 , the reflections from the gas-saturated region have greater amplitude than those from the brine-saturated region around the peak frequency. Therefore, the spectral decomposed section around the peak frequency can discriminate the gassaturated zone more clearly from the brine-saturated zone than conventional stacked section.

\section{Class 1 formation}

We analyzed the amplitude spectra for the medium with Class 1 AVO response of which reflection coefficients tends to decrease with increasing the incident angle. As shown in Fig. 6, the peak frequencies are located around $50 \mathrm{~Hz}$ for all incident angles of $0^{\circ}, 10^{\circ}$ and $25^{\circ}$. Oppositely to Class 3

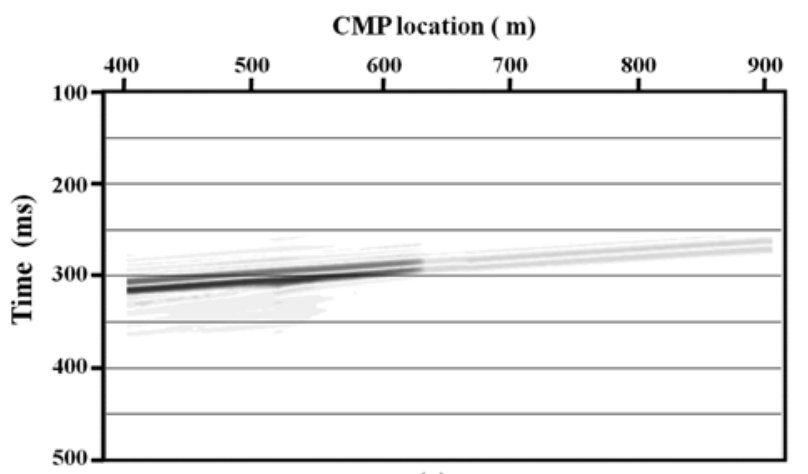

(a)

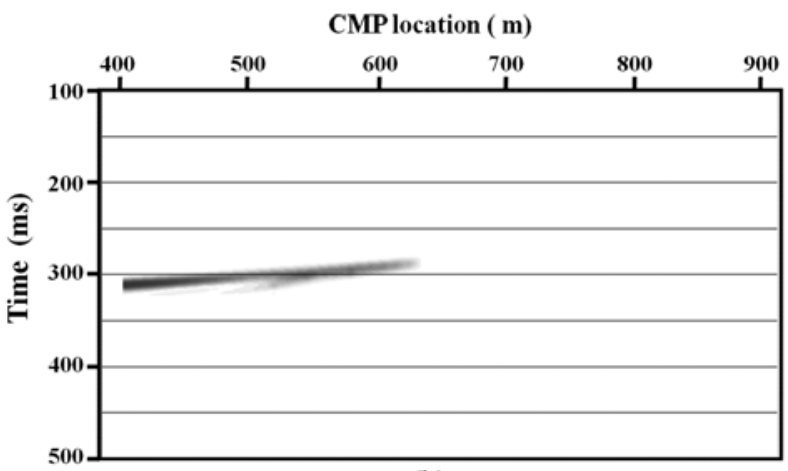

(b)

Fig. 8. (a) Stacked section with Class 1 medium. (b) Spectral decomposed section at $55 \mathrm{~Hz}$. response, the amplitude spectra are getting smaller with increasing of the incident angle. The maximum differences in the amplitude spectra between brine- and gas-saturated regions occur around the peak frequencies as in the case of Class 3 formation. However, the amplitude spectra of the

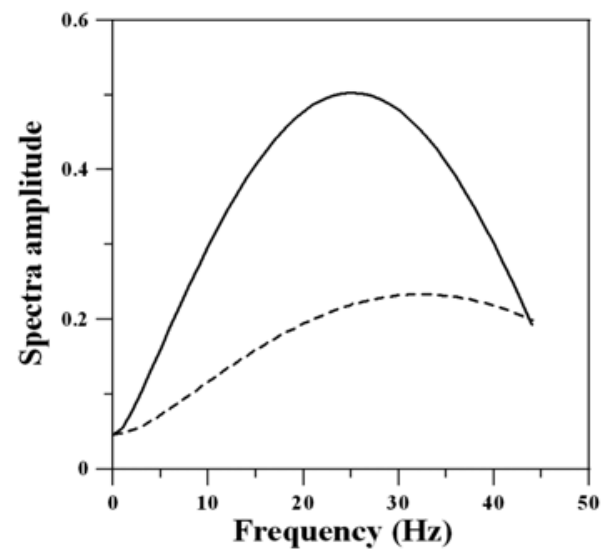

(a)

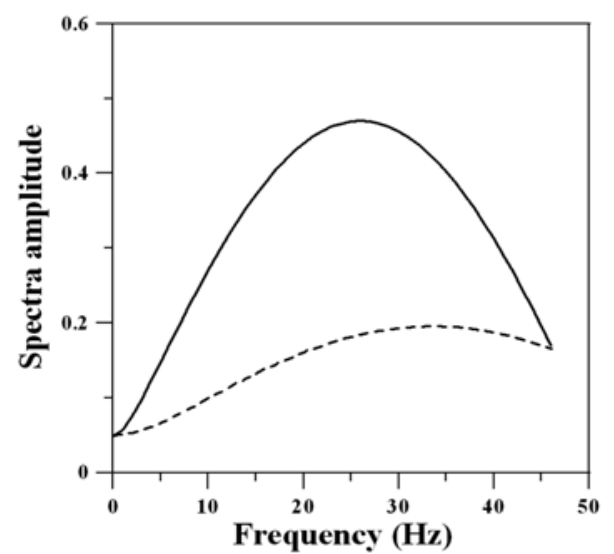

(b)

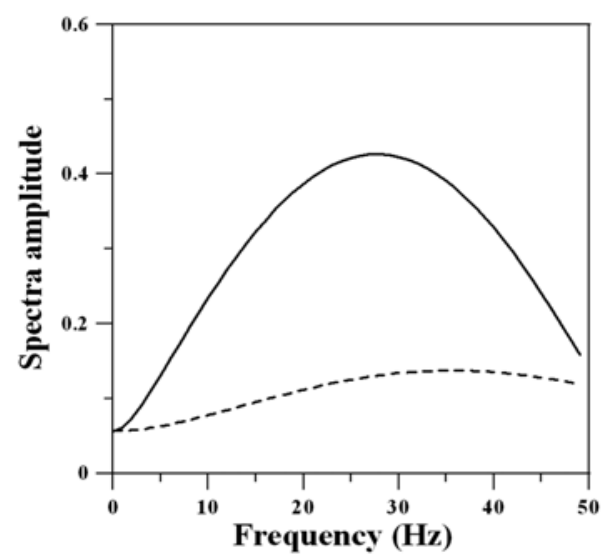

(c)

Fig. 9. The amplitude spectra of Class 4 with the variation of frequency at incident angle (a) $0^{\circ}$, (b) $15^{\circ}$ and (c) $25^{\circ}$. Dashed and solid lines indicate brine- and gas-saturated thin layers, respectively. 
brine-saturated thin layer (dashed line) are greater than those of the gas-saturated thin layer (solid line) for almost all frequencies. Spectral diagrams of brine- and gas-saturated zone shown in Fig. 7 show this feature clearly. In Fig. 7, the data from a dipping thin reservoir shown in Fig. 4 were used. The geometry was the same as Class 3 formation case, and, for the velocities of the media, Class 1 case in Table 1 were used. Fig. 8a shows a reflection from the dipping thin reservoir in the stacked section. Only with the reflection in

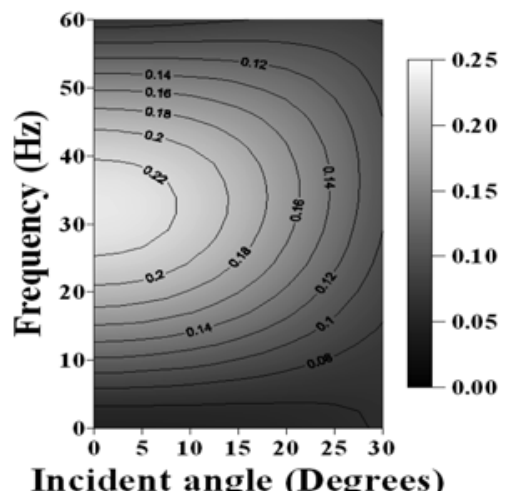

(a)

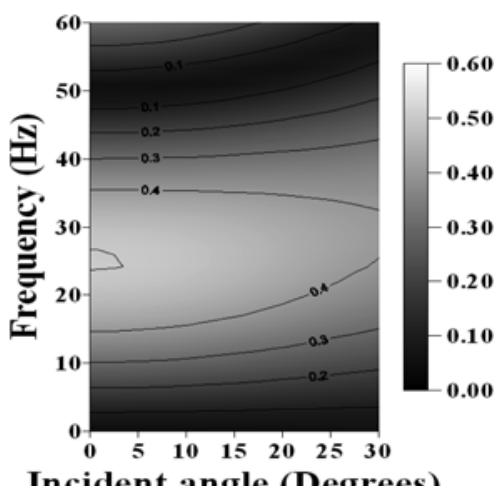

Incident angle (Degrees)

(b)

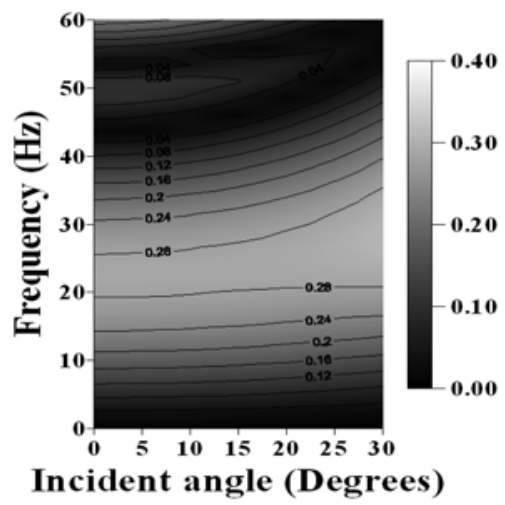

(c)

Fig. 10. Spectral diagrams of (a) brine-saturated and (b) gas-saturated zones for Class 4 formation with the variation of the frequency and the incident angle. (c) is the difference between (a) and (b). Note the scale bars indicate amplitude value. the stacked section, the gas-saturated region in the reservoir cannot be identified. However, the gas-saturated region can be easily distinguished from the brine-saturated region in the spectral decomposed section at $55 \mathrm{~Hz}$ which is around the peak frequency (Fig. 8b). Note that the reflections from the brine-saturated region have greater amplitude than those from gas-saturated region for Class 1 reservoir while the reflections from the brine-saturated region have smaller amplitude than those from the gas-saturated region for Class 3 reservoir.

\section{Class 4 formation}

Finally, we have analyzed the amplitude spectrum function for the medium with Class 4 AVO response of which absolute reflection coefficients tends to decrease with increasing the incident angle. As same as the previous cases, the maximum difference in the amplitude spectrum between the brine- and gas-saturated thin layers occurs around the peak frequencies regardless of incident angle (Fig. 9). One can easily misunderstand that the amplitude spectrum response of Class 3 and Class 4 might have different trend due to the trend of AVO for each case is considerably different. However, in the case of Class $4 \mathrm{AVO}$, similar phenomenon as like

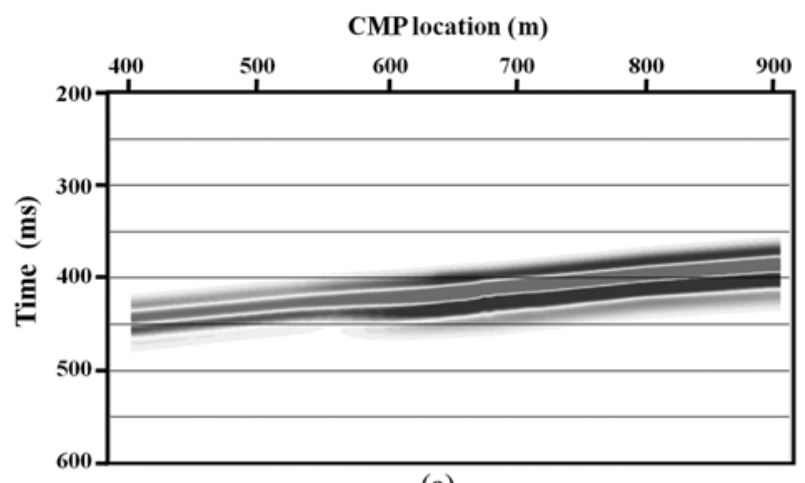

(a)

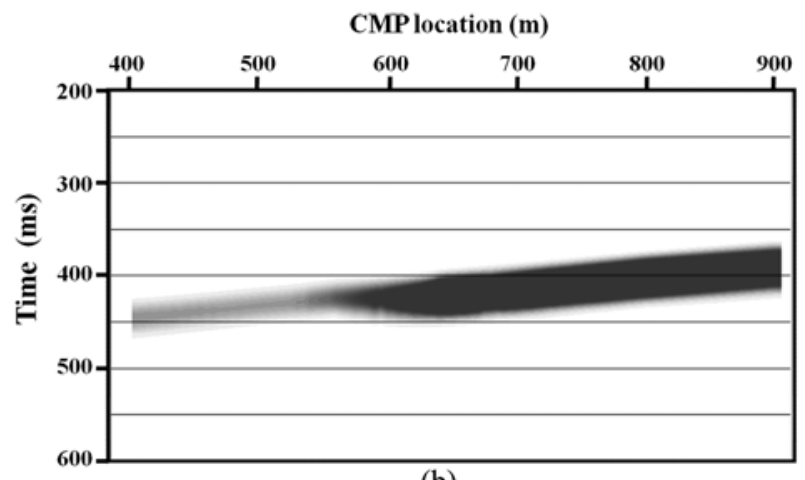

(b)

Fig. 11. (a) Stacked section with Class 4 medium. (b) Spectral decomposed section at $25 \mathrm{~Hz}$. 
Class 3 case observed as shown in Fig. 9 and Fig. 10. That is, the amplitude spectra of the gas-saturated thin layer (solid line) are greater than those of the brine-saturated one around the peak frequencies regardless of the incident angle (Fig. 9 and Fig. 10). Fig. 11(a) is the stacked section which was generated by using the same geometry and velocities for Class 4 as listed in Table 1. Even though the reflection event in Class 4 case is more discriminable than the one in the Class 3 case (Fig. 5(a)), it is still not easy to distinguish the gas-saturated zone from the brine-saturated one in the stack section. In comparison with the Fig. 11(a), gas-saturated zone is rather discriminable from the brine-saturated zone in the decomposed section at $25 \mathrm{~Hz}$ (Fig. 11(b)).

\section{Conclusions}

To detect gas-saturated region of a thin reservoir in a stacked section by using conventional direct hydrocarbon indicator or AVO analysis has difficulties because the reflections from the top boundary of the thin reservoir are interfered by the reflection from its bottom boundary. To solve this problem, we examined the amplitude spectrum function of the thin-layer reflection for different pore fluids and incidence angles. For all Class 3, Class 1 and Class 4 formations, the amplitude spectra have the periodicity depending on the velocity of the thin layer. In addition, the amplitude spectra have different values depending on the pore fluid, and the maximum difference in the amplitude spectrum between the brine- and gas-saturated zones occurs around its peak frequency regardless of the type of the pore fluid and AVO response. However, the amplitude spectra values from the gas-saturated thin layer are greater than those of the brine-saturated zone for Class 3 and Class 4 formations while the amplitude spectrum values of the gassaturated zone are smaller than those of the brine-saturated zone for Class 1 formation. Based on these features, the gassaturated region of a thin reservoir, which cannot be detected easily in a stacked section due to the tuning effect, can be effectively identified in a spectral decomposed section at the peak frequency.

\section{Acknowledgement}

This work was supported by the Energy Efficiency \& Resources of the Korea Institute of Energy Technology Evaluation and Planning (KETEP) grant funded by the Korea government Ministry of Knowledge Economy (No. 2009T100200049). The author thank for GX technology and parallel geoscience to use their own software. Also, the author would like to appreciate Dr. Soon Jee Seol for valuable discussion.

\section{References}

Castagna, J. P., Sun, S., and Siegfried, R., 2003, Instantaneous spectral analysis: Detection of low-frequency shadows associated with hydrocarbons, The Leading Edge, 22, 120-127.

Hilterman, F. J., 2001, Seismic amplitude interpretation: distinguished instructor series, No.4: EAGE.

Liu, Y., and Marfurt, K. J., 2006, Thin bed thickness prediction using peak instantaneous frequency, 76th Ann International Meeting, Soc. Expl. Geophys., Expanded Abstract, 968-972.

Liu, Y., and Schmitt, D. R., 2003, Amplitude and AVO responses of a single thin bed, Geophysics, 68, 1161-1168.

Li, Y., and Zheng, X., 2008, Spectral decomposition using Wigner-Ville distribution with applications to carbonate reservoir characterization, The Leading Edge, 28, 1050-1057.

Marfurt, K. J., and Kirlin, R. L., 2001, Narrow-band spectral analysis and thin-bed tuning, Geophysics, 66, 1274-1283.

Partyka, G. A., Gridley, J. A., and Lopez, J. A., 1999, Interpretational aspects of spectral decomposition in reservoir characterization, The Leading Edge, 18, 353-360.

Ralston, M., Rauch-Davies, M., Kuang, L., Xia, H., and Yang, D., 2007, General Method to Reduce Cross-Term Interference in the Wigner-Ville Decomposition, 77th Ann International Meeting, Soc. Expl. Geophys., Expanded Abstract, 870-874.

Ren, H., Goloshubin, G., and Hilterman, F., 2007, Spectral cross plot, 77th Ann International Meeting, Soc. Expl. Geophys., Expanded Abstract, 199-203.

Wu, X., and Liu, T., 2009, Spectral decomposition of seismic data with reassigned smoothed pseudo Wigner-Ville distribution, Journal of Applied Geophysics, 68, 386-393. 